\section{Cureus}

Received 07/29/2015

Review began 07/31/2015

Review ended 08/04/2015

Published 08/12/2015

\section{(C) Copyright 2015}

Nisar et al. This is an open access article distributed under the terms of the Creative Commons Attribution License CC-BY 3.0., which permits unrestricted use, distribution, and reproduction in any medium, provided the original author and source are credited.

\title{
Association of Diabetic Neuropathy with Duration of Type 2 Diabetes and Glycemic Control
}

Muhammad Umer Nisar ${ }^{1}$, Ambreen Asad ${ }^{2}$, Ahmed Waqas ${ }^{3}$, Nazia Ali ${ }^{4}$, Anam Nisar ${ }^{5}$, Mohsin A. Qayyum ${ }^{4}$, Hafsa Maryam ${ }^{6}$, Mohsin Javaid ${ }^{4}$, Mohsin Jamil ${ }^{4}$

1. Medical Student, Yusra Medical and Dental College, Islamabad, Pakistan 2. Associate Professor, Dept. of Physiology, Yusra Medical \& Dental College Near Kahuta Morr, GT Road, P.O Humak, Islamabad 3. Department of Psychiatry, CMH Lahore Medical College and Institute of Dentistry 4. Fourth year MBBS Student, Yusra Medical \& Dental College Near Kahuta Morr, GT Road, P.O Humak, Islamabad 5. Wah Medical College,, POF Hospital Wah Cantt. Pakistan 6. Fourth year MBBS, Yusra Medical \& Dental College Near Kahuta Morr, GT Road, P.O Humak, Islamabad

$\square$ Corresponding author: Muhammad Umer Nisar, umar8000@hotmail.com Disclosures can be found in Additional Information at the end of the article

\section{Abstract}

Introduction: Diabetes mellitus is associated with severe microvascular and macrovascular complications with major implications for public health. Diabetic neuropathy is a very problematic complication of diabetes mellitus. It is associated with severe morbidity, mortality, and a huge economic burden. The present study was designed with two aims: 1) to analyze the association of diabetic neuropathy with the glycemic index (levels of fasting blood glucose, random blood glucose, and $\mathrm{Hb} 1 \mathrm{Ac}$ ) in patients with Type 2 diabetes, and 2) to analyze the association of diabetic neuropathy with time passed since the diagnosis of diabetes.

Methods: This case-control study was undertaken between June 2013 and February 2015 in the Armed Forces Institute of Rehabilitation Medicine (AFIRM), Rawalpindi, Pakistan. Type 2 diabetics with an age range of 30-60 years were recruited from outpatient departments of AFIRM, Rawalpindi. Data were collected and recorded on a form with four sections recording the following: 1) demographics of patients and number of years passed since diagnosis of diabetes; 2) clinical examination for touch, pressure, power, pain, vibration, and ankle reflex; 3) nerve conduction studies for motor components of the common peroneal nerve and tibial nerve and the sensory component of median nerve and sural nerve; 4) glycemic index, including fasting blood glucose levels (BSF), random blood glucose (BSR) levels, and HbA1c levels. Data were analyzed in SPSS v. 20. Chi-square and phi statistics and logistic regression analysis were run to analyze associations between diabetic neuropathy and time passed since diagnosis of diabetes and glycemic index.

Results: In total, 152 patients were recruited. One-half of those patients had neuropathy (76 patients) and the other half (76 patients) had normal nerve function. The mean (standard deviation [SD]) duration of diabetes was nine years (6.76), BSF levels $7.98 \mathrm{mmol} / \mathrm{l}$ (2.18), BSR 9.5 mmol/1 (3.19), and HbA1c 6.5\% (2.18). Logistic regression analysis predicted $87.5 \%$ of the model correctly. Duration since the diagnosis of diabetes and HbA1c levels were significantly associated with the diagnosis of neuropathy in diabetics.

Conclusion: The presence of diabetic neuropathy was significantly associated with HbA1c levels and the duration of diabetes. 
Categories: Internal Medicine, Neurology, Preventive Medicine

Keywords: diabetes, diabetic neuropathy, peripheral neuropathy, diabetes mellitus, type 2 diabetes

\section{Introduction}

In recent years, diabetes mellitus has become a serious public health concern in the developing world. In 2014, the nationwide prevalence of diabetes mellitus was estimated at $6.8 \%$ in Pakistan, with 87,548 diabetes-related deaths and a mean expenditure of \$56 (USD) per person [1]. Therefore, diabetes poses a huge economic burden in Pakistan and this situation is projected to worsen with time.

Diabetes mellitus is a group of metabolic diseases associated with chronic hyperglycemia, which occurs as a consequence of destructive lesions of the pancreatic beta cells causing insufficient insulin secretion and several other etiological processes leading to decreased insulin sensitivity [2]. Subsequently, a plethora of metabolic derangements ensues that are further associated with several complications, such as retinopathy, neuropathy, nephropathy, macrovascular diseases [3], and depression [4]. These complications, if unchecked, may lead to potential blindness, foot ulcers, Charcot joints, amputations, and sexual dysfunction. In a low resourced country like Pakistan, about 3.5 million diabetics often go undiagnosed [1] and thus are at a higher risk of developing related complications.

Diabetic neuropathy is a very problematic complication of diabetes mellitus, associated with great morbidity, mortality, and a huge economic burden. Shera, et al. reported the prevalence of diabetic neuropathy to be $39.6 \%$ in Karachi [5]. Diabetic neuropathy consists of a family of neurological syndromes that affect specific regions of the nervous system, occurring in both Type 1 and Type 2 diabetes mellitus and also in acquired diabetes [6]. Its occurrence is explained by a multifactorial etiology that includes up-regulation of the polyol pathway, functional and structural microvascular disturbances, nervous and ganglionic hypoxia, increased oxidative stress, impairment in glycosylation of axonal and microvascular proteins, and impaired trophic factors required for peripheral nerves and their ganglia [8]. The San Antonio Convention divides neurological disturbances related to diabetes mellitus into subclinical neuropathy, assessed by anomalies in electrodiagnostic and quantitative sensory testing, and diffuse clinical neuropathy, involving distal sensorimotor and autonomic dysfunction and focal syndromes [7].

Neuropathy is associated with several risk factors, such as raised triglyceride levels, body mass index, smoking, hypertension [9], and diabetic microvascular [10] and macrovascular injuries

[11]. Lack of insulin or C-peptide or both also promotes severe axonal atrophy and loss of axons [12]. Mismanagement of this complication can further lead to foot ulceration; a harbinger of gangrenous limb loss. According to the diabetic wound classification system proposed by Armstrong, et al., risk of amputation is increased by 1.7 times in the case of diabetic neuropathy, 12 times in case of deformity, and 36 times if there is a history of previous ulceration [13]. Progression of diabetes mellitus and associated complications can be controlled with good glycemic control by the patient. According to the Diabetes Control and Complications Trial Research Group, intensive therapeutic management of insulin-dependent diabetes reduces the onset and progression of diabetic complications by $35-70 \%$ [14]. There is overwhelming evidence that early insulin therapy provides neuroprotective effects in patients with Type 2 diabetes who have diminished insulin secretion [15].

The present study was designed with two aims: 1) to analyze the association of diabetic neuropathy with glycemic index (levels of fasting blood glucose, random blood glucose, and $\mathrm{Hb} 1 \mathrm{Ac}$ ) in patients with Type 2 diabetes, and 2) to analyze the association of diabetic neuropathy with time passed since diagnosis of diabetes. 


\section{Materials And Methods}

This case-control study was undertaken between June 2013 and February 2015 in the Armed Forces Institute of Rehabilitation Medicine, Rawalpindi, Pakistan. Ethical approval was sought from the Ethical Review Committee of Yusra Medical and Dental College, Islamabad. One hundred and fifty-two patients with Type 2 diabetes were included in the study from the outpatient department of AFIRM, Rawalpindi. Due to limited resources, we could not ensure random sampling.

The minimum sample size required for this study was calculated to be 101 using the formula $\mathrm{N}=$ $10 \mathrm{k} / \mathrm{p}$ where $\mathrm{k}$ is the number of covariates $(\mathrm{k}=4)$, and $\mathrm{p}$ is the proportion of the smallest number of cases in the population $(\mathrm{p}=0.39)$ [16].

Written consent was obtained from all patients following a comprehensive explanation of the purposes of the study. Inclusion criteria were: patients with previously diagnosed Type 2 diabetes and aged between 30-60 years with an intact site for testing for nerve conduction studies. Patients with serious illnesses or any other co-morbidities, musculoskeletal disorders, diagnosed or suspected neuropathy due to any other cause, and patients taking drugs that may have interfered with study results in any way were excluded from the study. After the medical history was recorded, the subjects underwent a detailed physical examination, which included checking the patient for vibration, touch, ankle jerk, and power of limbs by experienced physicians and authors, including MUN, MJ, MJ, NA, MAQ, and HM. A battery of tests, including blood glucose random (BSR), blood glucose fasting (BSF), and HbA1C, by pathologists in the hospital on an ADVIA-1800 apparatus and nerve conduction studies (NCS) by experienced clinicians on a MEDULAR DEVICE were conducted. Based on NCS results, the subjects were classified as either having a neuropathy or not. Those patients with diabetes with normal nerve function were taken as controls.

Data were collected and recorded on a pre-tested form with four sections: The first section assessed the number of years since diabetes was diagnosed. The respondents provided the data on the duration since diagnosis which could add recall bias. Therefore, the duration since diagnosis of diabetes was confirmed by reviewing the patient records to eliminate any recall bias. The second section recorded the data from the clinical examination for touch, pressure, power, pain, vibration, and ankle reflex. These were recorded as normal, decreased, or absent. The third section recorded NCS for motor components of the common peroneal nerve and tibial nerve as well as the sensory component of the median and sural nerves. Patients were recorded as normal if the NCS on all of the above nerves were normal, as having mild neuropathy if one sensory or one motor nerve conduction speed was abnormal or absent, as having moderate neuropathy if two or three nerve conduction speeds were abnormal or absent, and as severe if conduction abnormalities were present in all four nerves. The fourth section recorded the glycemic index of the recruited subjects, which included BSR, BSF and HbA1c levels.

Data were analyzed in SPSS v. 20. BSR, BSF, HbA1c, and duration since diagnosis of diabetes mellitus were dichotomized. These dichotomized variables had the following cut-off values: BSR (11.09 mmol/l), BSF (6.93 mmol/l), HbA1c (6.5\%), and duration since diagnosis (three years). Results of the physical examination for touch, pressure, power, and ankle reflex were dichotomized as normal/abnormal. Chi-square and phi statistics were run to analyze the association of BSR levels, BSF levels, duration since diagnosis of diabetes, and HbA1c levels with the presence of neuropathy in patients with diabetes.

Then, these dichotomous variables (BSF, BSR, HbA1c levels, and duration since diagnosis) were introduced into a logistic regression model with a diagnosis of diabetic neuropathy (yes/no) as a dependent variable. 


\section{Cureus}

\section{Results}

There were a total of 152 patients. Seventy-six patients (50.0\%) had neuropathic conditions and 76 (50.0\%) had normal nerve function. The mean (standard deviation [SD]) duration of diabetes was nine years (6.76), BSF levels $7.98 \mathrm{mmol} / \mathrm{l}$ (2.18), BSR $9.5 \mathrm{mmol} / \mathrm{l}$ (3.19), and HbA1c $6.5 \%$ (2.18). Detailed results of these variables with frequencies and Chi-square values are reported in Table 1. Chi-square analysis revealed a statistically significant, positive and moderate association between diabetic neuropathy and BSF levels greater than $6.9 \mathrm{mmol} / \mathrm{l}(\varphi=$ $0.337, \mathrm{P}<0.001)$, BSR levels greater than $11.1 \mathrm{mmol} / \mathrm{l}(\varphi=0.493, \mathrm{P}<0.001)$, duration of diabetes greater than three years $(\varphi=0.456, \mathrm{P}<0.001)$, a strongly positive association of diabetic neuropathy with HbA1c levels $>6.5 \%(\varphi=0.71, \mathrm{P}<0.001)$, and abnormal results of the physical examination for touch $(\varphi=0.74, \mathrm{P}<0.001)$, pressure $(\varphi=0.632$, $\mathrm{P}<0.001)$, power $(\varphi=0.782$, $\mathrm{P}<$ $0.001)$, and ankle reflex $(\varphi=0.57, \mathrm{P}<0.001)$. Results of NCS tests also showed good association with diagnosis of neuropathy as assessed by the clinician.

Variable

Diabetics with Neuropathy $(\mathrm{n}=76)$

Control Group $(\mathrm{n}=76)$

P-value

Frequency (n)

Percentage (\%)

Percentage (\%)

\section{Laboratory Tests}

BSR mmol/l

$\leq 11.1$

37

$>11.1$

39

$34.3 \%$

$88.6 \%$

$28.8 \%$

$63.4 \%$

$17.1 \%$

$88.6 \%$

68

8

$82.9 \%$

$<.001$

$>6.5 \%$

62

Duration (years)

$\leq 3$

4

$>3$

72

$10.5 \%$

$63.2 \%$

34

$89.5 \%$

$<.001$

Physical Examination

\section{Power}

Normal

13

Abnormal

63

Touch

Normal

12

64
$15.3 \%$

$94 \%$

$15 \%$

$88.9 \%$
72

68

8
$65.7 \%$

$<.001$

$11.4 \%$

$71.2 \%$

$<.001$

$36.6 \%$

$11.4 \%$

$36.8 \%$

42

Abnormal

$88.9 \%$




\section{Cureus}

Ankle reflex

Normal

Abnormal

43

Pressure

Normal

26

Abnormal

50

$92.6 \%$

Clinical Diagnosis

Normal

1

Neuropathic

75

$1.5 \%$

65

$87.2 \%$

\section{TABLE 1: Frequency distribution of results, duration and diagnosis}

Frequency distribution of results of laboratory tests, duration since diagnosis, results of physical examination and clinical diagnosis in patients with diabetes with neuropathy and control group as assessed by NCS/EMG tests $(n=152)$

A logistic regression was performed to ascertain the effects of BSR, BSF, HbA1c levels, and duration since diagnosis of diabetes on the likelihood that participants have diabetic neuropathy. These covariates predicted $87.5 \%$ of the model correctly. Out of four predictor variables, only two were statistically significant: HbA1c and duration since diagnosis of diabetes (Table 2). Diabetics with duration of more than three years since diagnosis of diabetes were 7.8 times more likely and diabetics with $\mathrm{HbA1c}$ levels greater than $6.5 \%$ were 16.9 times more likely to develop neuropathy. HbA1c levels were the strongest predictor of diabetic neuropathy. 


\section{Cureus}

\begin{tabular}{|c|c|c|c|c|c|}
\hline Variables & B & P value & Odds Ratio & Lower Cl & Upper CI \\
\hline \multicolumn{6}{|c|}{ Random blood sugar levels (mmol/l) } \\
\hline$\leq 11.1$ & 1.3 & 0.048 & 1 & & \\
\hline$>11.1$ & & & 3.7 & 1.01 & 13.34 \\
\hline \multicolumn{6}{|c|}{ Fasting blood sugar levels (mmol/l) } \\
\hline$\leq 6.9$ & 0.37 & 0.487 & 1 & & \\
\hline$>6.9$ & & & 1.4 & 0.51 & 4.06 \\
\hline \multicolumn{6}{|c|}{ HbA1c levels (\%) } \\
\hline$\leq 6.5$ & 2.83 & $<0.001$ & 1 & & \\
\hline$>6.5$ & & & 16.9 & 5.71 & 50.10 \\
\hline \multicolumn{6}{|c|}{ Duration (years) } \\
\hline$\leq 3$ & 2.1 & 0.003 & 1 & & \\
\hline$>3$ & & & 7.8 & 1.99 & 31.81 \\
\hline Constant & -3.4 & $<0.001$ & 0.032 & & \\
\hline
\end{tabular}

\section{TABLE 2: Binary logistic regression model with nerve function status (normal/neuropathic) as dependent variable $(n=152)$}

Cox \& Snell R Square $=0.491$, Negelkerke R Square $=0.654 ;$ Hosmer \& Lemeshow Test: $P=0.102$, Model $P$ value $<0.001$

According to the logistic regression analysis, diabetic neuropathy exhibited a weak and marginally significant association with BSR levels $(\mathrm{P}=.048)$. Diabetics with BSR levels > 11.1 $\mathrm{mmol} / \mathrm{l}$ had 3.7 times (95\% CI= $1.01-13.34)$ higher odds to exhibit neuropathy.

\section{Discussion}

Diabetic neuropathy is a severe complication of diabetes, and it is associated with multiple risk factors. This study evaluated the association of duration of diabetes mellitus and glycemic control with diabetic peripheral neuropathy. According to our analysis, both poor glycemic control and longer duration were significantly associated with diabetic neuropathy.

A long duration of diabetes and poor glycemic control is associated with increased production of glycosylation end products, metabolic derangements, endothelial injury, and oxidative products [17-18]. Oguejiofor, et al. found a lower prevalence of polyneuropathy in those with duration of $\mathrm{DM}<5$ years and highest in those with a duration of DM > 15 years [19]. A large study in the UK showed that neuropathy was present in as many as 36\% people with duration of diabetes greater than 10 years as compared to $20 \%$ when duration of diabetes was five years [20]. Sensory neuropathy and the extent of skin denervation also increases with duration of diabetes [21]. The association between the duration of diabetes mellitus and neuropathy was 
also evident in a research study on the epidemiology of diabetic complications [22].

In the present study, a logistic regression model consisting of duration of diabetes, $\mathrm{HbA1c}, \mathrm{BSF}$, and BSR predicted $87.5 \%$ of the occurrence of diabetic neuropathy in the study sample. Patients with an HbA1c > 6.5\% were 16.9 times more likely to develop neuropathy. The role of poor glycemic control and chronic hyperglycemia as a risk factor for diabetic neuropathy has also been established in several longitudinal studies [23-24]. The severity of hyperglycemia and abnormal glycemic hemoglobin levels considerably affect the results of the sensory and motor NCS tests [25]. This might be due to the fact that abnormal levels of HbA1c are positively associated with neuromuscular jitters and fiber densities [26]. These variations in HbA1c are also associated with other diabetic complications as evident in a multicenter study, which has established variation in $\mathrm{HbA1C}$ to be an important risk factor of diabetic retinopathy [27]. Tight blood glucose control significantly reduced the risk of microvascular complications in the Diabetes Control and Complications Trial (DCCT), which showed that intensive insulin therapy reduced incidence of albuminuria by 54\% and decreased mean risk of retinopathy by $76 \%$ [14]. The United Kingdom Prospective Diabetes Study (UKPDS) showed that the intense glucose control group had a $25 \%$ reduction in the risk of microvascular complications endpoints. Furthermore, UKPDS showed that keeping HbA1c at a mean of $7 \%$ over 10 years significantly reduced the risk of microvascular complications [28]. These studies also recommend a target HbA1c as close to normal as possible, which provides improved outcomes [14, 29]. The UKPDS showed that HbA1c below $6 \%$ had the lowest risk for diabetes-related complications and for every $1 \%$ decrease in the mean $\mathrm{HbA1c}$, there was a $37 \%$ decrease in microvascular complications [29]. Patients in the UKPDS who were intensively treated for diabetes and maintained an HbA1c below $7 \%$ had a 12\% decrease in diabetes-related microvascular events. The Action in Diabetes and Vascular Disease (ADVANCE) trial showed that after a five-year follow-up in an intensively treated group with mean $\mathrm{HbA1c}$ of $6.5 \%$ as compared to a standard treated group with mean HbA1c of 7.3\%, there was an decreased incidence of microvascular events ( $9.4 \%$ vs. $10.9 \%$; hazard ratio: 0.86 ), especially because of the decreased incidence of nephropathy (4.1\% vs. 5.2\%; hazard ratio, 0.79 ) [30]. Glycemic control significantly affects the rate of progression from microalbuminuria to proteinuria and from overt nephropathy to ESRD [31]. A prospective study in Japan divided patients into two groups: multiple insulin injections group (MIT) and conventional insulin injection group (CIT). This study showed a decreased risk of nephropathy and retinopathy and an improvement in neurological tests like NCS in the MIT group while the CIT group showed deterioration in nerve conduction velocities and vibration threshold. The study concluded that keeping HbA1c at about $6.5 \%$ by multiple insulin injection therapy can delay the onset and the progression of diabetic microvascular events [32]. DCCT showed that, with a median HbA1c of $7 \%$, there is $35-76 \%$ reduction in the early stages of microvascular disease [33]. Tight glycemic control is required to prevent microvascular and macrovascular complications, which is particularly effective in the early phase of disease [34]. These studies show tight glycemic control, which is measured by HbA1c as the most important factor to decrease microvascular events. Diabetic neuropathy is also associated with several other risk factors, including age, smoking, serum cholesterol levels, cardiovascular disease, increased diastolic blood pressure, severe ketoacidosis, raised levels of fasting triglyceride, proliferative diabetic retinopathy, and increase in urine albumin [35]. Intensive multifactorial long-term interventions have been proved to slow progression of auto autonomic neuropathy, nephropathy, and retinopathy and reduce the risk of cardiovascular disease [36-37].

There is overwhelming evidence that timely screening with earlier detection and intervention would be useful in preventing the progression of neuropathy and reduced risk of complication in other organs [38-39]. Effective communication between healthcare professionals and patients with diabetes can greatly reduce the morbidity and mortality associated with diabetes. This has also been highlighted by Mahdad, et al. who found compelling evidence of improvement in glycemic control, redox, and inflammatory status of diabetic patients after a three-month lifestyle advice follow-up [40]. After a rigorous literature review, Basit, et al. 
devised "BRIGHT" guidelines for self-monitoring of blood glucose levels, which highly individualizes the therapeutic regimen for patients with diabetes by accurate assessment of metabolic control, forming realistic goals, and preventing chronic complications and cognitive decline [41]. To increase compliance in Pakistani diabetic patients, their attitudes, concerns and fears regarding the etiology, progression, efficacy, and side effects of insulin and oral hypogylcemics should be properly addressed by sharing information adequate to their literacy levels and culture.

\section{Conclusions}

Diabetic neuropathy is a very problematic complication of diabetes. It is significantly associated with $\mathrm{HbA1c}$ levels and duration of diabetes.

\section{Additional Information \\ Disclosures}

Human subjects: Consent was obtained by all participants in this study. Ethical Review Committee, Yusra Medical and Dental College Islamabad. issued approval N/A. Animal subjects: All authors have confirmed that this study did not involve animal subjects or tissue. Conflicts of interest: In compliance with the ICMJE uniform disclosure form, all authors declare the following: Payment/services info: Research proposal won Rupees 10,000 at 9th Annual Neurology Conference at Shifa College of Medicine, Islamabad, Pakistan. Financial relationships: All authors have declared that they have no financial relationships at present or within the previous three years with any organizations that might have an interest in the submitted work. Other relationships: All authors have declared that there are no other relationships or activities that could appear to have influenced the submitted work.

\section{Acknowledgements}

We thank Pamela Waltl (AuthorAID in the Eastern Mediterranean) for improving the use of English in the text.

\section{References}

1. International Diabetes Federation. IDF Diabetes Atlas . (2014). Accessed: July 29, 2015: http://www.idf.org/diabetesatlas.

2. Committee of the Japan Diabetes Society on the Diagnostic Criteria of Diabetes Mellitus, Seino Y, Nanjo K, Tajima N, Kadowaki T, Kashiwagi A, Araki E, Ito C, Inagaki N, Iwamoto Y, Kasuga M, Hanafusa T, Haneda M, Ueki K: Report of the Committee on the Classification and Diagnostic Criteria of Diabetes Mellitus. J Diabetes Investig. 2010, 1:212-228. 10.1111/j.20401124.2010.00074.x

3. Orchard TJ, Dorman JS, Maser RE, Becker DJ, Drash AL, Ellis D, LaPorte RE, Kuller LH: Prevalence of complications in IDDM by sex and duration pittsburgh epidemiology of diabetes complications study II. Diabetes. 1990, 39:1116-24. 10.2337/diab.39.9.1116

4. Mezuk B, Eaton WW, Albrecht S, Golden SH: Diabetes care depression and type 2 diabetes over the lifespan: a meta-analysis. Diabetes Care. 2008, 31:2383-90. 10.2337/dc08-0985

5. Shera AS, Jawad F, Maqsood A, Jamal S, Azfar M, Ahmed U: Prevalence of chronic complications and associated factors in type 2 diabetes. J Pak Med Assoc. 2004, 54:54-9.

6. Dyck PJ, Kratz KM, Karnes JL, Litchy WJ, Klein R, Pach JM, Wilson DM, O'Brien PC, Melton LJ 3rd, Service FJ: The prevalence by staged severity of various types of diabetic neuropathy, retinopathy, and nephropathy in a population-based cohort: the Rochester Diabetic Neuropathy Study. Neurology. 1993, 43:817-24. 10.1212/WNL.43.4.817

7. Consensus Panel of American Diabetes Association and American Academy of Neurology: Consensus statement: Report and recommendations of the San Antonio conference on diabetic neuropathy. American diabetes association american academy of neurology. Diabetes 
Care. 1988, 11:592-7.

8. Zochodne DW: Diabetic neuropathies: Features and mechanisms. Brain Pathol. 1999, 9:36991. 10.1111/j.1750-3639.1999.tb00233.x

9. Tesfaye S, Chaturvedi N, Eaton SE, Ward JD, Manes C, Ionescu-Tirgoviste C, Witte DR, Fuller JH, EURODIAB Prospective Complications Study Group: Vascular risk factors and diabetic neuropathy. NEJM. 2005, 352:341-50. 10.1056/NEJMoa032782

10. Siemionow M, Demir Y: Diabetic neuropathy: pathogenesis and treatment. J Reconstr Microsurg. 2004, 20:241-52. 10.1055/s-2004-823112

11. Singh A, Donnino R, Weintraub H, Schwartzbard A: Effect of strict glycemic control in patients with diabetes mellitus on frequency of macrovascular events. Am J Cardiol. 2013, 112:1033-38. 10.1016/j.amjcard.2013.05.04

12. Sima AA, Sugimoto K: Experimental diabetic neuropathy: an update. Diabetologia. 1999, 42:773-88. 10.1007/s001250051227

13. Armstrong DG, Lavery LA, Harkless LB: Validation of a diabetic wound classification system. The contribution of depth, infection, and ischemia to risk of amputation. Diabetes Care. 1998, 21:855-59. 10.2337/diacare.21.5.855

14. The Diabetes Control and Complications Trial Research Group: The effect of intensive treatment of diabetes on the development and progression of long term complications in insulin dependent diabetes mellitus. NEJM. 1993, 329:977-986.

10.1056/NEJM199309303291401

15. Partanen J, Niskanen L, Lehtinen J, Mervaala E, Siitonen O, Uusitupa M: Natural history of peripheral neuropathy in patients with non-insulin-dependent diabetes mellitus. NEJM. 1995, 333:89-94. 10.1056/NEJM199507133330203

16. Peduzzi P, Concato J, Kemper E, Holford TR, Feinstein AR: A simulation study of the number of events per variable in logistic regression analysis. J Clin Epidemiol. 1996, 49:1373-1379. 10.1016/S0895-4356(96)00236-3

17. Nishikawa T, Edelstein D, Du XL, Yamagishi S, Matsumura T, Kaneda Y, Yorek MA, Beebe D, Oates PJ, Hammes HP, Giardino I, Brownlee M: Normalizing mitochondrial superoxide production blocks three pathways of hyperglycaemic damage. Nature. 2000, 404:787-790. $10.1038 / 35008121$

18. Soulis T, Thallas V, Youssef S, Gilbert RE, McWilliam BG, Murray-McIntosh RP, Cooper ME: Advanced glycation end products and their receptors co-localise in rat organs susceptible to diabetic microvascular injury. Diabetologia. 1997, 40:619-28. 10.1007/s001250050725

19. Oguejiofor OC, Odenigbo CU, Oguejiofor CB: Evaluation of the effect of duration of diabetes mellitus on peripheral neuropathy using the United Kingdom screening test scoring system, bio-thesiometry and aesthesiometry. Niger J Clin Pract. 2010, 13:240-47.

20. Young MJ, Boulton AJ, MacLeod AF, Williams DR, Sonksen PH: A multicentre study of the prevalence of diabetic peripheral neuropathy in the United Kingdom hospital clinic population. Diabetologia. 1993, 36:150-154. 10.1007/BF00400697

21. Shun CT, Chang YC, Wu HP, Hsieh SC, Lin WM, Lin YH, Tai TY, Hsieh ST: Skin denervation in type 2 diabetes: correlations with diabetic duration and functional impairments. Brain. 2004, 127:1593-605. 10.1093/brain/awh180

22. Maser RE, Steenkiste AR, Dorman JS, Nielsen VK, Bass EB, Manjoo Q, Drash AL, Becker DJ, Kuller LH, Greene DA: Epidemiological correlates of diabetic neuropathy. Report from Pittsburgh Epidemiology of Diabetes Complications Study. Diabetes. 1989, 38:1456-61. 10.2337/diab.38.11.1456

23. Dyck PJ, Davies JL, Wilson DM, Service FJ, Melton LJ 3rd, O'Brien PC: Risk factors for severity of diabetic polyneuropathy: intensive longitudinal assessment of the Rochester Diabetic Neuropathy Study cohort. Diabetes Care. 1999, 22:1479-86. 10.2337/diacare.22.9.1479

24. Adler AI, Boyko EJ, Ahroni JH, Stensel V, Forsberg RC, Smith DG: Risk factors for diabetic peripheral sensory neuropathy. Results of the Seattle Prospective Diabetic Foot Study. Diabetes Care. 1997, 20:1162-7. 10.2337/diacare.20.7.1162

25. Hsu HY, Chiu HY, Lin HT, Su FC, Lu CH, Kuo LC: Impacts of elevated glycemic hemoglobin and disease duration on the sensorimotor control of hands in diabetes patients. Diabetes Metab Res Rev. 2015, 31:385-94. 10.1002/dmrr.2623

26. Chang CW, Chuang LM: Correlation of HbA1c concentration and single-fiber EMG findings in diabetic neuropathy. Electromyogr Clin Neurophysiol. 1996, 36:425-32.

27. Hermann JM, Hammes HP, Rami-Merhar B, Rosenbauer J, Schütt M, Siegel E, Holl RW, DPV 
Initiative the German BMBF Competence Network Diabetes Mellitus: HbA1c variability as an independent risk factor for diabetic retinopathy in type 1 diabetes: a German/Austrian multicenter analysis on 35,891 patients. PLoS One. 2014, 9:e91137-10.

10.1371/journal.pone.0091137

28. Turner RC, Holman RR, Cull CA, Stratton IM, Matthews DR, Frighi V, Manley SE: Intensive blood glucose control with sulphonylureas or insulin compared with conventional treatment and risk of complications in patients with type 2 diabetes (UKPDS 33). Lancet. 1998, 352:83753. 10.1016/S0140-6736(98)07019-6

29. Stratton IM, Adler AI, Neil HA, Matthews DR, Manley SE, Cull CA, Hadden D, Turner RC, Holman RR: Association of glycaemia with macrovascular and microvascular complications of type 2 diabetes (UKPDS 35): prospective observational study. BMJ. 2000, 321:405-12. 10.1136/bmj.321.7258.405

30. ADVANCE Collaborative Group, Patel A, MacMahon S, Chalmers J, Neal B, Billot L, Woodward M, Marre M, Cooper M, Glasziou P, Grobbee D, Hamet P, Harrap S, Heller S, Liu L, Mancia G, Mogensen CE, Pan C, Poulter N, Rodgers A, Williams B, Bompoint S, de Galan BE, Joshi R, Travert F: Intensive blood glucose control and vascular outcomes in patients with type 2diabetes. NEJM. 2008, 358:2560-72. 10.1056/NEJMoa0802987

31. Fioretto P, Bruseghin M, Berto I, Gallina P, Manzato E, Mussap M: Renal protection in diabetes: Role of glycemic control. JASN. 2006, 17:S86-S89. 10.1681/ASN.2005121343

32. Ohkubo Y, Kishikawa H, Araki E, Miyata T, Isami S, Motoyoshi S, Kojima Y, Furuyoshi N, Shichiri M: Intensive insulin therapy prevents the progression of diabetic microvascular complications in Japanese patients with non-insulin-dependent diabetes mellitus: a randomized prospective 6-year study. Diabetes Res Clin Pract. 1995, 28:103-17. 10.1016/01688227(95)01064-K

33. Nathan DM: Epidemiology of Diabetes Interventions and Complications Study at 30 Years . Diabetes Care. 2014, 37:9-16. 10.2337/dc13-2112

34. Cheung NW1, Conn JJ, d'Emden MC, Gunton JE, Jenkins AJ, Ross GP, Sinha AK, Andrikopoulos S, Colagiuri S, Twigg SM; Australian Diabetes Society: Position statement of the Australian Diabetes Society: individualisation of glycated haemoglobin targets for adults with diabetes mellitus. Med J Aust. 2009, 191:339-44.

35. Tesfaye S, Stevens LK, Stephenson JM, Fuller JH, Plater M, Ionescu-Tirgoviste C, Nuber A, Pozza G, Ward JD: Prevalence of diabetic peripheral neuropathy and its relation to glycaemic control and potential risk factors: the EURODIAB IDDM Complications Study. Diabetologia. 1996, 39:1377-84. 10.1007/s001250050586

36. Gaede P, Vedel P, Parving HH, Pedersen O: Intensified multifactorial intervention in patients with type 2 diabetes mellitus and microalbuminuria: the Steno type 2 randomised study. Lancet. 1999, 353:617-22. 10.1016/S0140-6736(98)07368-1

37. Gaede P, Vedel P, Larsen N, Jensen GV, Parving HH, Pedersen O: Multifactorial intervention and cardiovascular disease in patients with type 2 diabetes. NEJM. 2003, 348:383-93. 10.1056/NEJMoa021778

38. Bansal D, Gudala K, Muthyala H, Esam HP, Nayakallu R, Bhansali A: Prevalence and risk factors of development of peripheral diabetic neuropathy in type 2 diabetes mellitus in a tertiary care setting. J Diabetes Investig. 2014, 5:714-21. 10.1111/jdi.12223

39. Schellhase KG, Koepsell KD, Weiss NS: Glycemic control and the risk of multiple microvascular diabetic complications. Fam Med. 2005, 37:125-30.

40. Mahdad N, Boukortt FO, Benzian Z, Bouchenak M: Lifestyle advice follow-up improve glycemic control, redox and inflammatory status in patients with type 2 diabetes. Journal of Diabetes and Metabolic Disorders ultiple Microvascular Diabetic Complications. J Diabetes Metab Disord. 2014, 13:122. 10.1186/s40200-014-0122-1

41. Basit A, Khan A, Khan RA: BRIGHT guidelines on self-monitoring of blood glucose . Pak J Med Sci. 2014, 30:1150-55. 10.12669/pjms.305.6006 